This item was submitted to Loughborough's Research Repository by the author.

Items in Figshare are protected by copyright, with all rights reserved, unless otherwise indicated.

\title{
In pursuit of a 'Whole Brain' approach to undergraduate teaching: implications of the Herrmann brain dominance model
}

\section{PLEASE CITE THE PUBLISHED VERSION}

http://dx.doi.org/10.1080/03075079.2016.1152463

\section{PUBLISHER}

(C) Society for Research into Higher Education. Published by Taylor \& Francis (Routledge)

\section{VERSION}

AM (Accepted Manuscript)

\section{PUBLISHER STATEMENT}

This work is made available according to the conditions of the Creative Commons Attribution-NonCommercialNoDerivatives 4.0 International (CC BY-NC-ND 4.0) licence. Full details of this licence are available at: https://creativecommons.org/licenses/by-nc-nd/4.0/

\section{LICENCE}

CC BY-NC-ND 4.0

\section{REPOSITORY RECORD}

Hughes, Mathew, Paul Hughes, and lan Hodgkinson. 2019. "In Pursuit of a 'whole Brain' Approach to Undergraduate Teaching: Implications of the Herrmann Brain Dominance Model”. figshare. https://hdl.handle.net/2134/20358. 


\title{
In Pursuit of a 'Whole Brain’ Approach to Undergraduate Teaching: Implications of the Herrmann Brain Dominance Model
}

\author{
Mathew Hughes \\ Durham University Business School \\ Durham University \\ Mill Hill Lane \\ Durham DH1 3LB \\ United Kingdom \\ Tel: +44 (0) 1913345906 \\ Email: Mat.Hughes@durham.ac.uk

\section{Paul Hughes} \\ Durham University Business School \\ Durham University \\ Mill Hill Lane \\ Durham DH1 3LB \\ United Kingdom \\ Tel: +44 (0) 1913345393 \\ Email: Paul.Hughes@durham.ac.uk
}

\section{Ian R. Hodgkinson (corresponding author)}

School of Business and Economics

Loughborough University

Loughborough LE11 3TU

United Kingdom

Tel: +44 (0) 1509223865

Email: I.R.Hodgkinson@lboro.ac.uk

Word count: 7,603 


\title{
IN PURSUIT OF A ‘WHOLE BRAIN’ APPROACH TO UNDERGRADUATE TEACHING: IMPLICATIONS OF THE HERRMANN BRAIN DOMINANCE MODEL
}

\begin{abstract}
The question of 'how we learn' continues to direct scholarly debate, yet undergraduate teaching is typically designed to homogenise the learning environment. This is despite heterogeneous learning outcomes ensuing for students, owing to their different learning styles. Accordingly, we examine the relationship between teaching methodologies and learning styles. Drawing on the Herrmann Brain Dominance Instrument and the theory of 'whole-brain' teaching, we find a suite of teaching methodologies that are generic across learning styles-tutorials, group work, firmoriented case studies, game playing, reading journal papers, handouts, PowerPoint slides, in-class examples, in-class short exercises, and videos - and find a group of teaching methodologieslectures, seminars, people-oriented case studies, creative problem-solving, reading textbooks, guest speakers, in-class small group exercises, homework, role play, problem-based learning, self-directed learning, project-based learning, and class debates - that target and develop specific learning styles. Implications of the ‘whole brain’ model for teaching and learning are discussed.
\end{abstract}

Keywords: learning styles; teaching methodologies; Herrmann; brain dominance model; undergraduate teaching. 


\section{Introduction}

A persistent problem facing educators is designing classes that encourage students to engage with material and to learn deeply, richly, and to seek out independent learning opportunities. Nadkarni (2003) among others provide evidence that the closer the match between individuals’ preferred learning style and the learning activities they are exposed to, the more likely individuals are to learn, but is that really the case? The question of 'how we learn' continues to direct scholarly debate (Hodge, Wright, Barraket, Scott, Melville, and Richardson, 2011). In order to manage students’ learning styles therefore, we need to delve into the relationship between teaching methodologies and learning styles to understand how these styles can be developed (Jaju, Kwak, and Zinkhan, 2002). Specifically, we need to understand whether learning styles can be targeted and developed through teaching methods adopted to enrich the learning experience (Herrmann, 1996). This represents the research objective of this study.

At present, classes are typically designed in ways that try to homogenise the learning experience for students; for example, by holding regular hour-long lectures or hour-long case study sessions. An assumption typically prevails that learners will exhibit uniformity in the ways in which they process and organise information (learning style), their preference towards particular teaching methodologies (instructional preferences), and the actions they employ to deal with the demands of specific learning situations (Sadler-Smith and Smith, 2004). In doing so, there is a risk of ignoring the fact that students are heterogeneous in how they process information, approach learning tasks, and tackle problems or learning opportunities (Herrmann, 1989; Sadler-Smith and Smith, 2004), which ultimately impacts how they learn and how they develop robust knowledge structures from learning encounters (Coffield, Moseley, Hall, and Ecclestone, 2004). At worst, the design of classes risk alienating sections of the class whose learning styles are incompatible with the instructional method, or, classes will simply tap and augment specific learning styles at the expense of others.

Effective learning takes place when teaching methodologies (Prosperpio and Gioia, 2007), learning experiences (Stein, Isaacs, and Andrews, 2006), and learning environments (Drea, Tripp, and Stuenkul, 2005) are aligned with students’ learning styles. While course design is traditionally informed by arguments for teaching material that facilitate deep and independent learning, little integration exists between course design and students’ heterogeneous preferred learning activities, because these are informed by difficult-to-decipher cognitive dominances in 
the brain (Herrmann, 1989, 1990, 1996). Accordingly, the relationship between teaching methodologies and students' cognitive dominances or preference for a particular learning style represents an important gap in theory.

However, the literature has failed to provide a common conceptual framework or reach agreement on a decisive framework to lead research (Sternberg, 2001). Still, critical reviews (e.g. Coffield et al., 2004) have found one model in particular to be useful and powerful compared to most - the Herrmann Brain Dominance Instrument (HBDI) model. The central premise behind the model is that the brain is designed to be whole and as such, learning requires a balance of its four core skills (based on the four quadrants of the brain) (Herrmann, 1989, 1990). In effect, it warns against using teaching methodologies that tap only limited cognitive skills and preferences as this undermines the learning experience. Yet, the pedagogical (lecture, teacher-directed teaching) and andragogical (learner-centered and self-directed teaching) (Knowles, 1984) implications of the ‘whole brain' model have been under-researched (Hall and Moseley, 2005). As such its potential to improve the quality of teaching and learning has not yet been substantiated in a rigorous manner (Coffield et al., 2004).

\section{Theory}

Not all students have the same learning styles as research from several disciplines has shown (Auyeung and Sands, 1996). As a consequence, the field of learning styles has emerged which seeks to understand how students approach learning opportunities and how they respond to alternative instructional methods.

In a review of the learning styles field, Coffield et al. (2004) report that a plethora of models suffer from conceptual and empirical problems, such as insufficient pedagogy, validity, and reliability owing to the fact that the field itself is not unified or critically assessed sufficiently. It therefore matters fundamentally which instrument is chosen because significant pedagogical impact will result. Since the Herrmann model is one of few to receive praise for its potential to help educators develop strategies to teach holistically (Coffield et al., 2004), our intention is to examine the merits of this lesser-known model.

Several theories assume biological determinism suggesting that learning preference precedes any exposure to teaching and learning (e.g., Kolb, 1976; Kolb and Fry, 1975) whereas others believe learning styles can be developed through teaching. Specifically, the way a person 
uses the specialised brain results from socialisation, including teaching, far more than from genetic inheritance (Herrmann, 1996). Hence, this view contradicts traditional thinking on learning models that presumes individuals are fixed in their learning preferences and posits that learning styles are fluid characteristics in individuals that can be shaped by teaching methods (Hall and Moseley, 2005). While brain dominance might lead a person to favor different types of teaching methodologies (learning style $\rightarrow$ teaching methods), equally each learning style could potentially be developed or stimulated by different teaching methods as well (teaching methods $\rightarrow$ learning style) (Coffield et al., 2004; Herrmann, 1989, 1996). We adopt this latter approach in line with Herrmann's theorisation, thus we do not view learning styles as a classificatory mechanism since the range of learning styles can be developed and stimulated to enrich learning of all students rejecting the notion of biological determinism.

\section{Herrmann 'whole brain' model for teaching and learning}

The HBDI model (Herrmann, 1989, 1996) was developed from research into electroencephalographic (EEG) assessment of the human brain (MacLean, 1952). Herrmann (1989) suggests that a person's learning style is determined by their brain dominance across the four quadrants of the brain (Herrmann, 1989; Lumsdaine and Binks, 2005). This model differs from the majority of others in that it views these brain dominances or learning preferences as cognitive skills that can be tapped and intentionally developed through a holistic teaching strategy. The model assumes that learning style is not fixed and as such learning is not path dependent regardless of a person’s dominant or preferred style (Coffield et al., 2004; Herrmann, 1989, 1990; Lumsdaine and Binks, 2005). Herrmann (1996) theorised that to enable people to learn holistically, it is necessary to ensure that the whole brain is used in the course of education so that students receive a well-rounded and challenging learning experience that draws on present and latent cognitive skills. For instance, even small rises in an educator's learning awareness can lead to enhanced learning experiences (Truuvert, 2014). However, there are few tests of its predictive validity or how the quadrants can be targeted by different teaching methods (Coffield et al., 2004).

There are four metaphorical quadrants to the brain based on the cerebral (upper-half) and limbic (bottom-half) parts of the human brain (Herrmann, 1989, 1990) (see Figure 1). Quadrant 'A' (cerebral, left: the rational self) represents factual, rational, logical, analytical and critical 
thinking; Quadrant 'B' (limbic, left: the safe-keeping self) captures organised, planned and controlled thinking; Quadrant 'C' (limbic, right: the feeling self) reflects intuitive, symbolic and a people-oriented approach; and, Quadrant ' $\mathrm{D}$ ' (cerebral, right: the experimental self) represents creativity and innovation, holistic, imaginative and strategic thinking. Critically, Coffield et al. (2004) and Herrmann (1996) emphasise that learning requires a balance of the four quadrants. Consequently, it is more of a dynamic model than most of its contemporaries, concerned with the process of learning rather than the product of learning (Coffield et al., 2004). Moreover, it is independent of cognitive ability and sees the different skills as active or latent in all, and so can be tapped by different teaching methodologies to enrich the learning experience. We thus conceptualise a student as a bundle of cognitive skills, which implicates that only by tapping the full range of learning styles through teaching methods can students learn richly and deeply.

\section{[Insert Figure 1 about here]}

\section{Study hypothesis}

Learning style is not fixed or set for the lifetime of an individual learner, different teaching methods may target specific learning preferences held but may also develop transition in student learning between styles thus increasing their learning repertoire (Hall and Moseley, 2005). Hence the composition of learning styles within the classroom can change depending on the teaching methods adopted and it is this view that separates the HBDI model from other more traditional learning models. The HBDI model is a planning tool as much as an analytical tool, such that different quadrants of the brain will respond to different activities in different ways. These are summarised in Table 1. A whole brain approach requires variation and rotation in activities to generate exposure to, rather than avoidance of, less-preferred activities (Lumsdaine and Binks, 2005). Only by stimulating a range of learning styles can we improve class engagement and thereby generate a positive experience across the classroom as a whole (Trigwell, Ellis, and Han, 2012).

\section{[Insert Table 1 about here]}


Herrmann (1989) did not hypothesise whether a common set of teaching methods might exhibit a relationship with, or preference by, any particular brain dominance or learning style. Nevertheless, we can begin to unpick these relationships by considering the characteristics' of the learning styles as depicted in the HBDI model. Quadrant ' $A$ ' thinkers tend to approach problems with factual, rational, logical, analytical, and critical thinking whereby decisions and actions are based on logical reasoning. As such, it implies that such a mindset would be congruent with facts, evidence, and problem-based learning techniques. Quadrant 'B' thinkers on the other hand tend to approach problems using organised, planned and controlled thinking techniques reflecting a degree of administration and a belief in what is tried and true. Accordingly, this may imply a preference towards structured tasks, particularly ones laden with details and facts. People with preferences for quadrant ' $\mathrm{C}$ ' approach problems, tasks, and learning opportunities with an intuitive, symbolic, and people-oriented approach and as such appear to revel in team-based work and prefer the study of people through case studies. Quadrant C thinkers would not typically be comfortable with activities that are diagonal to them (Figure 1) such that people with such dominances would struggle at logical and rational analysis because it is against their preference to think and act intuitively and emotively (Lumsdaine and Binks, 2005). People with a dominant preference for quadrant ' $D$ ' however approach tasks with holistic, imaginative and strategic thinking whereby people like to play with ideas and examine the 'big picture'. This implies that such people might appear to prefer creative problem-solving, out-ofthe-box thinking, and game-playing but may dislike specified reading due to its structured and organised nature (Lumsdaine and Binks, 2005).

There is prima facie reason to expect that different teaching methodologies are likely to hold different relationships for any one brain dominance. Still, whilst theory suggests that some learning styles might respond to specific teaching methods, the theory is too underdeveloped to hypothesise how these groupings will form. We therefore consider a variety of teaching methodologies and the implications of these for student learning styles, based on the HBDI model, to give some indication of the types of relationships that might exist.

The 'lecture' remains a cornerstone of teaching methodology, despite being derided as a poor means of educating students (Powell, 2003) and evidence exists to specify that a wellplanned lecture drawing on rich examples, diagrams, video clips, and illustrations can be effective in achieving learning objectives (Nadkarni, 2003). Herrmann (1989) suggests that a 
lecture might be preferred by quadrant B thinkers (capturing organisation and data driven skills); but a student might be able to approach the content with either an analytical approach, emotive approach, or strategic approach depending on whether additional teaching tools are deployed simultaneously. Also, whilst a lecture is valuable in educating students about the key principles and theory of a set of constructs, which is amenable to quadrants A and B, the content can later be explored further through such techniques as case studies, games and research, which appear more amenable to quadrants $\mathrm{C}$ and $\mathrm{D}$. Indeed, students typically need a degree of prior knowledge before they can explore concepts in more depth and engage meaningfully in alternative learning methodologies (Dochy, De Rijdt, and Dyck, 2002). Combining techniques that tap multiple cognitive skills therefore seems an effective way to improve students' learning.

Case-based teaching as an alternative to the traditional 'lecture' can develop rich insight into a small set of constructs or a particular phenomenon thereby stimulating students to develop their own insights and knowledge structures of the case topic (Greiner, Bhambri, and Cummings, 2003). It is possible that the angle or context of the case might be preferred by specific brain dominances though. For example, a case with accounting data or operational data would likely be preferred by quadrant B organisers but not by emotive, people-oriented quadrant C thinkers. Cases have been criticised for approaching learning through the limited prism of a theoretical discipline, small set of constructs, or a specific phenomenon (Greiner et al., 2003). Nevertheless, cases help students to develop mental models of phenomena; knowledge, skills and experience of how real people dealt with real problems; and can generate philosophies to guide their own future behavior and thus enhance or develop a range of cognitive skills (Liang and Wang, 2004). Indeed, studies show that students taught with such cooperative learning methods exhibit higherlevel reasoning and critical thinking skills, deeper understanding of learned material, and greater ability to view situations from others' perspectives (Quarstein and Peterson, 2001). Accordingly, deploying a variety of cases each with different perspectives (e.g., fact-based, people-oriented, firm-oriented) should tap and develop different cognitive skills.

Game-playing and simulations are regarded as a means of promoting generative rather than superficial learning (Zantow, Knowlton, and Sharp, 2005) and likely tap into the creative, strategic components of quadrant D thinkers. They provide students with substantial 'hands-on' experience, opportunities to practice decision-making, opportunities to engage theory in practical terms to solve problems in novel ways, and can also help make students more appreciative of the 
relevance of course content, or helping them to see the 'big' picture (Burke and Moore, 2003). Guest speaker sessions are another interactive teaching tool and enable real-life 'learning from experience’ for students (Metrejean, Pittman, and Zarzeski, 2002). Given this is typically a people-oriented exercise; it would most likely favor quadrant $\mathrm{C}$ thinkers.

Group-based exercises however might be the most difficult teaching methodology to deploy constructively with respect to differences among students’ learning styles. For example, Students might benefit from working in groups that consist of diverse learning styles ( $\mathrm{Mu}$ and Gnyawali, 2003). Indeed, each person can approach the task from their own preferred style whilst benefiting from the perspective of those with very different preferences. But, large cognitive differences in the ways group tasks are viewed, prioritised, and tackled and differences in the ways the problems are solved may lead to confrontation and poor integration of knowledge among individuals (Mu and Gnyawali, 2003). The type of group exercise might mitigate this problem. For example, short debates offer people to put forward their views whereas a timeconstrained short group exercise might favor that of an organised or analytical disposition.

In summary then, as a person is a blend of learning preferences a common set of teaching methods might exhibit a relationship with any particular brain dominance. Therefore as called for by Herrmann (1996) we explore the following hypothesis: Teaching methods can target and develop specific learning styles. In doing so we offer an alternative model that has been underresearched in education to better understand students and learning itself (Hall and Moseley, 2005).

\section{Research methodology}

The sample consisted of the business school undergraduate cohort of two major universities in the United Kingdom. Undergraduate students were chosen as key informants because these students tend to have a dependence orientation and are typically subject-centered, such that they are not comfortable with proactive learning (Nadkarni, 2003). These students will then rely more on their cognitive biases to determine their approach to learning (Herrmann, 1989, 1996).

Data were generated through a web-based questionnaire survey. Following instruction from the respective Director of Undergraduate Programmes at both institutions, the survey could only be distributed through the Undergraduate Office at each institution. The authors provided templates for all correspondence to the respective Undergraduate Office with the only tailoring 
being details of the endorsement of each institution for the completion of the survey. All survey communications were then emailed to students from the respective Undergraduate Office. An email explaining the purpose of the study and the importance of response was sent to the undergraduate cohorts of both business schools through the undergraduate office of each school first. This e-mail contained a hyperlink to the questionnaire. Following survey guidance suggested by Dillman, Smyth, and Christian (2014), two identical reminder emails were sent in the space of one month to reemphasise the importance of the study and of response. Each email emphasised anonymity, salience, and University endorsement for the research. No financial incentives were offered, however the value of the work in helping to design better classes for students was emphasised. In total, from University 1, 235 responses were received from a base of 1588 students resulting in a response rate of 14.8 percent; and from University 2, 179 responses were received from a base of 1106 students resulting in a response rate of 16.2 percent. Taken together the total number of eligible responses was 414 with an overall response rate of 15.4 percent. Of these respondents, 196 were male (47.3 percent) while 218 were female (52.7 percent); the average age was 19.7 years, with a range from 17 to 27 years; and 281 were home students and 132 were international students.

The Herrmann learning style constructs were operationalised using the definitions of each style along with scales drawn from Lumsdaine, Lumsdaine, and Shelnutt (1999) and Lumsdaine and Binks (2005) leading to a battery of 40 items, 10 for each cognitive skill. Students were asked, "Please choose between 12 and 30 of the following types of learning methods which you think best describe how you approach learn activities and go about your learning”. Selected statements were given a value of 1 ; statements not selected were given a value of 0 . We checked each statement to ensure that it captured its intended style and matched the style's definition. These items were also double-checked with academic experts familiar with the model to ensure accuracy. In our analysis, we created summated scores from the set of items for each learning style. For example, the count of selected items relating to a style was divided by the number of items (e.g., if 9 items were selected from a battery of 10 items then the score would be $9 / 10=$ 0.9). Also, a person can have more than one cognitive preference or learning style as mapped by Herrmann (Lumsdaine and Binks, 2005). Thus, we created additional summated scores based on vertical and horizontal combinations of the four quadrants (see E-H, Table 2). For example, the count of selected items relating to a combination of two styles were divided by the total number 
of items for each style (e.g., if 9 items were selected from a battery of 10 items for one style and 3 items selected for the second style then the score would be 12/20 =0.6). In doing this the scores are always standardised to range from 0-1. For teaching methodologies, 23 teaching methods were identified following a literature review, reflection, and discussion with educators. This list was again checked by academic experts to ensure exhaustiveness. These items took the form of Likert scales and were anchored ‘strongly dislike’ (1) to ‘strongly like’ (7).

Measurement items are listed in Appendix A, with the descriptive statistics presented in Appendix B.

Data analysis and hypothesis testing took the form of multiple linear regressions. With regression we are seeking to show that preferred teaching methods relate to (or not) one's brain dominance (learning style). The dependent variable was the learning style because we wanted to discover whether students' likings for teaching methodologies (the independent variables) were related positively or negatively in their relationship with each learning style. Eight models were created, each one representing a specific learning style or combination of styles.

\section{Results and analysis}

Our central hypothesis is thus: Teaching methods can target and develop specific learning styles. To interpret the results we examine whether any given teaching method is related to each brain dominance (learning style) in turn. These brain dominances, as measured, are captured as the student's approach to learning (learning style). Where any given teaching method positively relates to a given brain dominance then we can conclude that those teaching methods best fit with the student's approach to learning. Where any given teaching method has a non-significant relationship with any style or combination of styles, this can form the basis of a generic set of teaching methods. Those methods that are negatively related do not fit well with the student's approach to learning and therefore from an educator's perspective these methodologies are a means to stimulate the transition to alternative learning styles outside of the student's comfort zones by generating exposure to less preferred activities. Too much emphasis on such methods however may detract from the learning experience. From a course design point of view these results better enable educators to tailor course design to best fit with not only the learning styles of their students, but to also consciously target those learning styles that are in need of 
development for ‘whole brain’ benefits. As such, this approach addresses Herrmann’s (1996) wishes for understanding how to enrich the learning experience.

Table 2 contains the results. Both model fit and model explanatory power were acceptable and statistically significant in each instance, indicating that teaching methodologies significantly contribute to how students’ learn.

\section{[Insert Table 2 about here]}

Our results are two-fold. The first group of results reveal a set of teaching methodstutorials, group work, firm-oriented case studies, game playing, reading journal papers, handouts, PowerPoint slides, in-class examples, in-class short exercises, and videos - that exhibit no statistically significant relationship with any of the Herrmann learning styles or combinations of styles. These form the basis of a generic set of teaching methodologies that can be deployed by educators with the knowledge that students can approach and tackle each activity comfortably from their own cognitive preference. In terms of the learning experience, the student can gain from the activity in a manner proportional to the learning style which they choose to applybased on theory, this will typically be their dominant style. The challenge therefore comes from the nature of the task itself, but the drawback is that the student is not pushed to think and learn outside the box of their preferred learning style. Students may also exhibit wide variation in learning outcomes as each learning style will lead different people to draw different interpretations and alternative conclusions from the activity.

The second group of results reveal a set of teaching methods-lectures, seminars, peopleoriented case studies, creative problem-solving, reading textbooks, guest speakers, in-class small group exercises, homework, role play, problem-based learning, self-directed learning, projectbased learning, and class debates - that can be used to target and stimulate specific learning styles. These methods can be deployed with a view to develop and enhance a particular learning style (where a positive relationship exists) or alternatively to complicate or cloak a specific learning style to encourage a student to switch to another (where a negative relationship exists). Taken together, these methods engender a holistic, well-rounded approach to learning. For example, seminars, which are discussion driven and flexible in structure are negatively related to skills B (organised and data driven) and $\mathrm{H}$ (organised and data driven but with emotional 
attachment). Seminars then encourage such students to deploy alternative cognitive skills that they may not feel as comfortable with but are useful skills for them to develop. On the other hand, creative problem-solving helps to develop creative and strategic skills as captured in quadrant $\mathrm{D}$, and in the $\mathrm{C}+\mathrm{D}(\mathrm{F})$ and $\mathrm{A}+\mathrm{D}(\mathrm{G})$ combinations. While role play also has notable positive effects on quadrants $\mathrm{C}$ and $\mathrm{D}$ and in the $\mathrm{C}+\mathrm{D}$ combination (F). Together these teaching methods help develop a well-rounded learning experience by promoting creative and peopledriven skills. This is contrasted by formal lectures which affect analytical and data-driven skills (B and $A+B[E])$ positively and so encourage their development over other skills. The opposite is found with guest speakers, which implies that this tool encourages very different thought processes.

These findings show that by selecting a task that activates or challenges a specific learning style, educators can encourage students to deploy new or alternative skills outside their comfort zones. By implication, these methods help to develop well-rounded learners and help to develop skills critical for the students’ future employment. Equally, by tapping a specific mindset or skill, we may be able to reduce the variation in learning outcomes obtained by students as we synchronise and develop the use of alternative learning styles. Overall, we can use these findings to generate a whole-brain approach to teaching, develop more holistic learning environments and teaching encounters, and enrich the learning experience by ensuring that students learn multiplicatively, as suggested by Herrmann $(1989,1996)$ and advocated by Coffield et al. (2004) and Lumsdaine and Binks (2005). To illustrate, a class employing creative problem-solving and role play exercises for example would specifically target the quadrant D style of creativity and strategic thinking, and help develop that skill specifically, whereas use of lectures, textbooks, and small group exercises enhance skills A, B, and C specifically. Thus, by strategically developing classes with carefully selected teaching methodologies, the results show we can target and develop different learning styles based on Herrmann's $(1989,1996)$ theory and thereby enhance the roundedness of the students’ learning experience.

\section{Conclusions}

Our objective in this study was to understand whether teaching methods can target and develop specific learning styles to enrich the learning experience (Herrmann, 1996). We conclude that a 'whole-brain' approach is possible but depends on the strategic design of teaching methods to be 
incorporated into courses and modules, not simply a random selection of random activities. Coordinating combinations of methodologies in class allows us to transcend students' comfort zones, educate multiplicatively, and enrich the learning experience for students. Powell (2003) raises the problem of apathy in teaching environments. Such apathy can be addressed through combining generic teaching methods that students can approach based on their own cognitive preferences in conjunction with specific teaching methods that build upon specific skills and/or encourage transition to alternative learning styles beyond the dominant preference. With these techniques students are not made to feel uncomfortable with being directed into a different way of thinking but are rather guided by the teacher's 'invisible hand' to use alternative skills through different teaching methods. This reflects a more considered and sensitive way to manage students' learning. For example, in-class examples do not discriminate, nor do short exercises, but creative problem-solving and use of in-class small group exercises can tap specific quadrants of the brain and thus enrich the learning experience by intentionally targeting the development of students' skills. By drawing on a spectrum of generic and specific teaching strategies, we can create environments that engage the entire range of learning styles in our classrooms to give students both an appealing and a challenging teaching environment. Indeed, the development, retention, and sustainability of high student participation is important to active learning, and facilitating interaction and discussion among students is considered central to a well-structured course which inspires deep learning (Gibbs, 1992). This requires a balance of pedagogical (lecture, teacher-directed teaching) and andragogical (learner-centered and self-directed teaching) styles (Knowles, 1984), as our results indicate.

Interestingly the teaching methods that are often used within a course are not always the most appropriate for students 'whole brain' learning; rather they are a way of dealing with the large numbers of students that are now entering the higher education system. Therefore this study allows us to deal with this issue sensitively, and can help educators to learn to be 'smarter' in the delivery of their courses and the teaching methods they incorporate. That way, a blend of teaching methods or techniques can still be incorporated to the advantage of all students rather than a select number that are 'more comfortable' with an associated method based on their present preferred learning style. This opens the necessity for further training and support for educators to develop different teaching techniques capable of providing a 'whole-brain' learning environment. 


\section{Implications}

Implications from the findings are three-fold. First, teaching methods not amenable to any brain dominance are components of a general teaching strategy that educators can use. Students can then interpret the learning opportunities through their own preferred learning styles, develop their own unique views by reorganising information, and tackle the learning opportunity or task in ways that are comfortable to them. In contrast, teaching methods preferred by and associated with specific learning styles can be used to target specific quadrants of the brain that develop these skills, while exposure to, rather than avoidance of, less preferred activities for any one or combination of learning styles can create novel learning outcomes and enrich the learning experience.

Educators can use the results to develop a ‘whole-brain’ approach to teaching by designing courses that draw on general and dominance-specific methods and those methods that encourage transition to alternative learning styles. For example, combining lectures with detailed examples, in-class small group exercises, and problem-solving sessions followed by discussion or debate to assess understanding facilitates the development of analytical, people, and creative skills (brain quadrants). The results add fresh insight to the broader debate on learning styles, showing how selecting methods to target specific cognitive skills can trigger students to engage in deep learning (by stimulating core skills and then building on non-core skills to educate in a manner that transcends students’ cognitive comfort zones).

Introducing new forms of teaching and learning, such as problem-solving, improves not only on the academic experience of students but their potential future employability. Indeed, such an approach to teaching is recommended in the literature for enhancing learning and increasing the desirability of students for employers as they will possess more well-rounded skills in entering the workplace (Bigelow, 2004). As a consequence, teachers must understand that improving approaches to teaching does not simply benefit students in terms of academic experience but also employability and by implication, university reputation.

\section{Limitations and Future Research}

Several limitations affect this study. First, the study was cross-sectional. No claim of causality is made here, simply inferences toward statistically-relevant relationships. Longitudinal research 
may be of interest to track changes in preferences over time, if any, resulting from exposure to alternative teaching methods. Second, the validity of learning style inventories is based on the assumption that learners can accurately and consistently reflect how they process external stimuli and so define their internal cognitive processes (Price and Richardson, 2003). Ambiguity in a person's ability to adequately explain their learning style then may affect the results. Still, our methodology makes no assumptions as to a person's style as each respondent could select as many or as few of the learning style statements as they saw fit to characterise their approach to learning. Third, due to data limitations we do not specify how educators should choose when to use a generic method versus a method found to target or challenge a specific cognitive skill. Finally, the sample is taken from Business School undergraduate students in the UK, which may influence the relationships found particularly since exposure to teaching methods may vary between undergraduate and postgraduate provision, as well as between countries, and hence could influence how teaching methods target and develop learning styles.

Several directions for future research emerge from this study. First, can we as educators overburden our students with too much variation in activity? Although prevailing logic would suggest that variation enriches the learning environment and teaching experience-indeed we imply so in this study - it remains to be studied whether we might saturate students with too many or too much change in techniques. Second, our research does not delve into the academic performance of students with different learning preferences and whether this is moderated by the teaching method predominantly used. Conceivably, learning styles can be targeted and developed accordingly through alternative assessment methods and it is therefore possible that certain cognitive skills may be better targeted and developed by some assessment methods. Third, our analysis has not assessed whether there are gender differences across students. Herrmann (1989, 1996) and Lumsdaine and Binks (2005) note that females tend to be stronger at quadrant C (intuitive, emotional, people-oriented) and quadrant D (creative, big picture, strategic) learning than males who are more quadrant A (rational, logical, analytical) and quadrant B (organised, prefer charts and data) oriented. Future research might wish to explore related consequences for a holistic teaching strategy. Finally, many models of learning styles exist and a greater degree of synthesis is needed in the field of learning styles (Coffield et al., 2004). A meta-analysis of these models should create better knowledge of how students learn and the implications therein for teaching and learning. 
In closing, as Coffield et al. (2004) note, there is significant pedagogical impact depending on which learning styles model is chosen by educators. We have shown how an eclectic teaching strategy can be created to develop a 'whole-brain' approach to teaching to enrich the learning environment.

\section{References}

Auyeung, P., and Sands, J. 1996. A cross cultural study of the learning style of accounting students. Accounting and Finance 36, no. 2: 261-275.

Bigelow, J.D. 2004. Using problem-based learning to develop skills in solving unstructured problems. Journal of Management Education 28, no. 5: 591-609.

Burke, L.A., and Moore, J.E. 2003. A perennial dilemma in OB education: Engaging the traditional student. Academy of Management Learning \& Education 2, no. 1: 37-52.

Coffield, F., Moseley, D., Hall, E., and Ecclestone, K. 2004. Learning styles and pedagogy in post-16 learning: A systematic and critical review. London: Learning and Skills Research Centre.

Dillman, D.A., Smyth, J.D., and Christian, L.M. 2014. Internet, phone, mail, and mixed-mode surveys: the tailored design method. New York: Wiley.

Dochy, F., De Rijdt, C., and Dyck, W. 2002. Cognitive prerequisites and learning: How far have we progressed since Bloom? Implications for educational practice and teaching. Active Learning in Higher Education 3, no. 3: 265-284.

Drea, J.T., Tripp, C., and Stuenkel, K. 2005. An assessment of the effectiveness of an in-class game on marketing students' perceptions and learning outcomes. Marketing Education Review 15, no. 1: 25-34.

Gibbs, G. 1992. Improving the quality of student learning. Bristol: Technical Educational Services Ltd.

Greiner, L.E., Bhambri, A., and Cummings, T.C. 2003. Searching for a strategy to teach strategy. Academy of Management Learning \& Education 2, no. 4: 402-420.

Hall, E., and Moseley, D. 2005. Is there a role for learning styles in personalised education and training? International Journal of Lifelong Education 24, no. 3: 243-255.

Herrmann, N. 1989. The creative brain. North Carolina: The Ned Hermann Group.

Herrmann, N. 1990. The creative brain. Lake Lure, NC: Herrmann International. 
Herrmann, N. 1996. The whole brain business book. New York: McGraw-Hill.

Hodge, P., Wright, S., Barraket, J., Scott, M., Melville, R., and Richardson, S. 2011. Revisiting 'how we learn' in academia: practice-based learning exchanges in three Australian universities. Studies in Higher Education 36, no. 2: 167-183.

Jaju, A., Kwak, H., and Zinkhan, G. M. 2002. Learning styles of undergraduate business students: A cross-cultural comparison between the US, India, and Korea. Marketing Education Review 12, no. 2: 1-13.

Knowles, M.S. 1984. Andragogy in action. San Francisco, CA: Jossey-Bass.

Kolb, D.A. 1976. Learning style inventory: Technical manual. Boston: McBer.

Kolb, D.A., and Fry, R. 1975. Towards an applied theory of experiential learning. In C.L. Copper (Ed.), Theories of group processes. London: John Wiley.

Liang, N., and Wang, J. 2004. Implicit mental models in teaching cases: An empirical study of popular MBA cases in the United States and China. Academy of Management Learning \& Education 3, no. 4: 397-413.

Lumsdaine, E., and Binks, M. 2005. Entrepreneurship, creativity and effective problem solving: Keep on moving! Hancock, MI: E\&M Lumsdaine Solar Consultants Inc.

Lumsdaine, E., Lumsdaine, M., and Shelnutt, J.W. 1999. Creative problem solving and engineering design. Columbus, $\mathrm{OH}$ : McGraw-Hill.

MacLean, P.D. 1952. Some psychiatric implications of physiological studies on frontotemporal portion of limbic system (visceral brain). Electroencephalography and Clinical Neurophysiology 4, no. 4: 407-418.

Metrejean, C., Pittman, J., and Zarzeski, M.T. 2002. Guest speakers: Reflections on the role of accountants in the classroom. Accounting Education 11, no. 4: 347-364.

Mintzberg, H. 1976. Planning on the left side and managing on the right. Harvard Business Review 54, Jul-Aug: 49-57.

Mu, S., and Gnyawali, D.R. 2003. Developing synergistic knowledge in student groups. Journal of Higher Education 74, no. 6: 689-711.

Nadkarni, S. 2003. Instructional methods and mental models of students: An empirical investigation. Academy of Management Learning \& Education 2, no. 4: 335-351.

Powell, K. 2003. Spare me the lecture. Nature 425, no. 6955: 234-236. 
Price, L., and Richardson, J.T.E. 2003. Meeting the challenge of diversity: A cautionary tale about learning styles. In C. Rust (Ed.), Improving student learning theory and practice 10 years on. Oxford: Centre for Staff and Learning Development, Oxford Brookes University. Prosperpio, L., and Gioia, D.A. 2007. Teaching the virtual generation. Academy of Management Learning \& Education 6, no. 1: 69-80.

Quarstein, V.A., and Peterson, P.A. 2001. Assessment of cooperative learning: A goal-criterion approach. Innovative Higher Education 26, no. 1: 59-77.

Sadler-Smith, E., and Smith, P.J. 2004. Strategies for accommodating individuals' styles and preferences in flexible learning programmes. British Journal of Educational Technology 35, no. 4: 395-412.

Stein, S. J., Isaacs, G., and Andrews, T. 2004. Incorporating authentic learning experiences within a university course. Studies in Higher Education 29, no. 2: 239-258.

Sternberg, R.J. 1999. Thinking styles. Cambridge: Cambridge University Press.

Trigwell, K., Ellis, R.A., and Han, F. 2012. Relations between students' approaches to learning, experienced emotions and outcomes of learning. Studies in Higher Education 37, no. 7: 811824.

Truuvert, T. 2014. Enhancing tutorial learning experiences: a programme to develop sessionaltutor teaching skills by raising awareness about learning. Studies in Higher Education 39, no. 1: 20-33.

Zantow, K., Knowlton, D.S., and Sharp, D.C. 2005. More than fun and games: Reconsidering the virtues of strategic management simulations. Academy of Management Learning \& Education 4, no. 4: 451-458. 
Table 1. Design considerations (adapted from Coffield et al., 2004)

\begin{tabular}{l|l}
\hline Quadrant A & Quadrant D \\
Learns by: & Learns by: \\
Acquiring and quantifying facts & Taking initiative \\
Applying analysis and logic & Exploring hidden possibilities \\
Thinking through ideas & Self-discovery \\
Building cases & Constructing concepts \\
Forming theories & Synthesising content \\
& Learners respond to: \\
Learners respond to: & Spontaneity \\
Formalised lecture & Free flow \\
Data-based content & Experiential opportunities \\
Financial/technical case discussions & Experimentation \\
Textbooks and bibliographies & Playfulness \\
Programmed learning & Future-oriented case discussions \\
Behaviour modification & Visual displays \\
& Individuality \\
& Being involved \\
\hline Quadrant B & Quadrant C \\
& \\
Learns by: & Learns by: \\
Organising and structuring content & Listening and sharing ideas \\
Sequencing content & Integrating experiences with self \\
Evaluating and testing theories & Moving and feeling \\
Acquiring skills through practice & Harmonising with the content \\
Learners respond to: & Emotional involvement \\
Thorough planning & Learners respond to: \\
Sequential order & Experiential opportunities \\
Organisational and administrative & Sensory movement \\
case discussions & Music \\
Textbooks & People-oriented case discussions \\
Behaviour modification & Group interaction \\
Programmed learning & \\
Structure & \\
Lectures & \\
\hline
\end{tabular}


Table 2. Summary results of hypothesis test

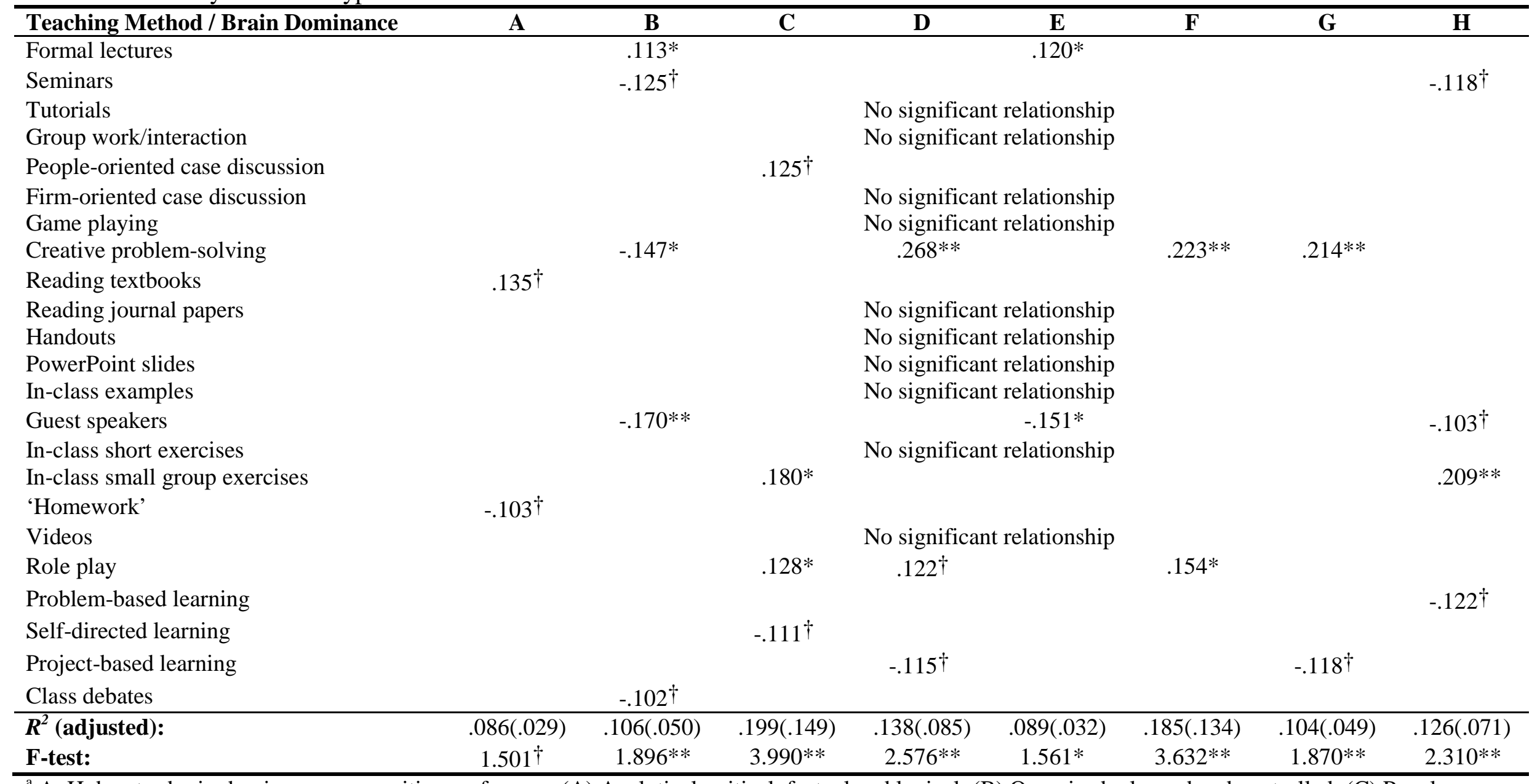

${ }^{\mathrm{a}}$ A-H denotes brain dominance or cognitive preference: (A) Analytical, critical, factual and logical; (B) Organised, planned and controlled; (C) Peopleoriented, intuitive and emotional; (D) Creative and imaginative; (E) Focused on detail (A+B); (F) Big picture person (C+D); (G) Analytical but imaginative $(\mathrm{A}+\mathrm{D})$; (H) Organised but value people $(\mathrm{B}+\mathrm{C}) .{ }^{* *} p<0.01 ;{ }^{*} p<0.05 ;{ }^{\dagger} p<0.1$ 
Figure 1. Herrmann's learning styles model

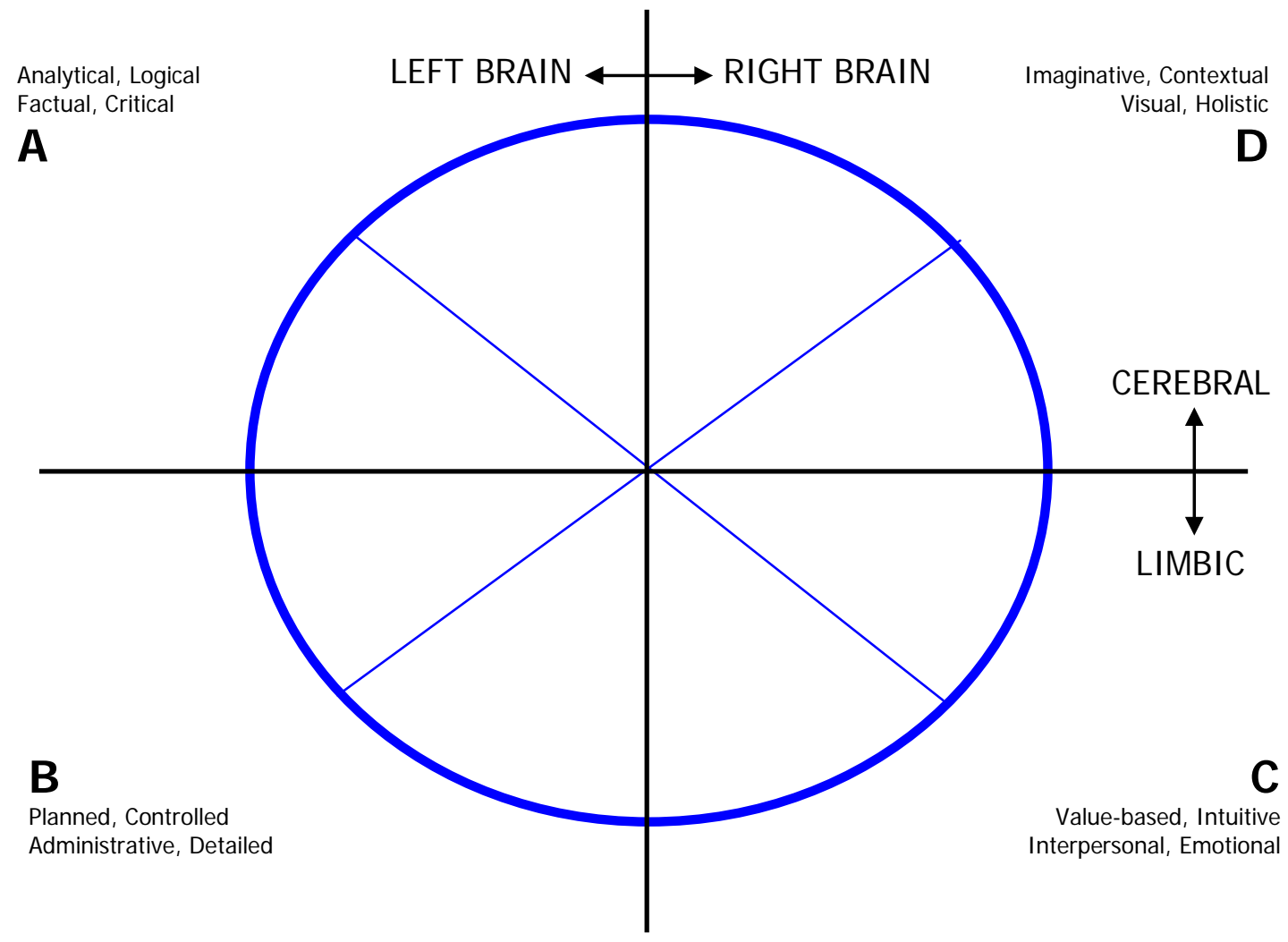




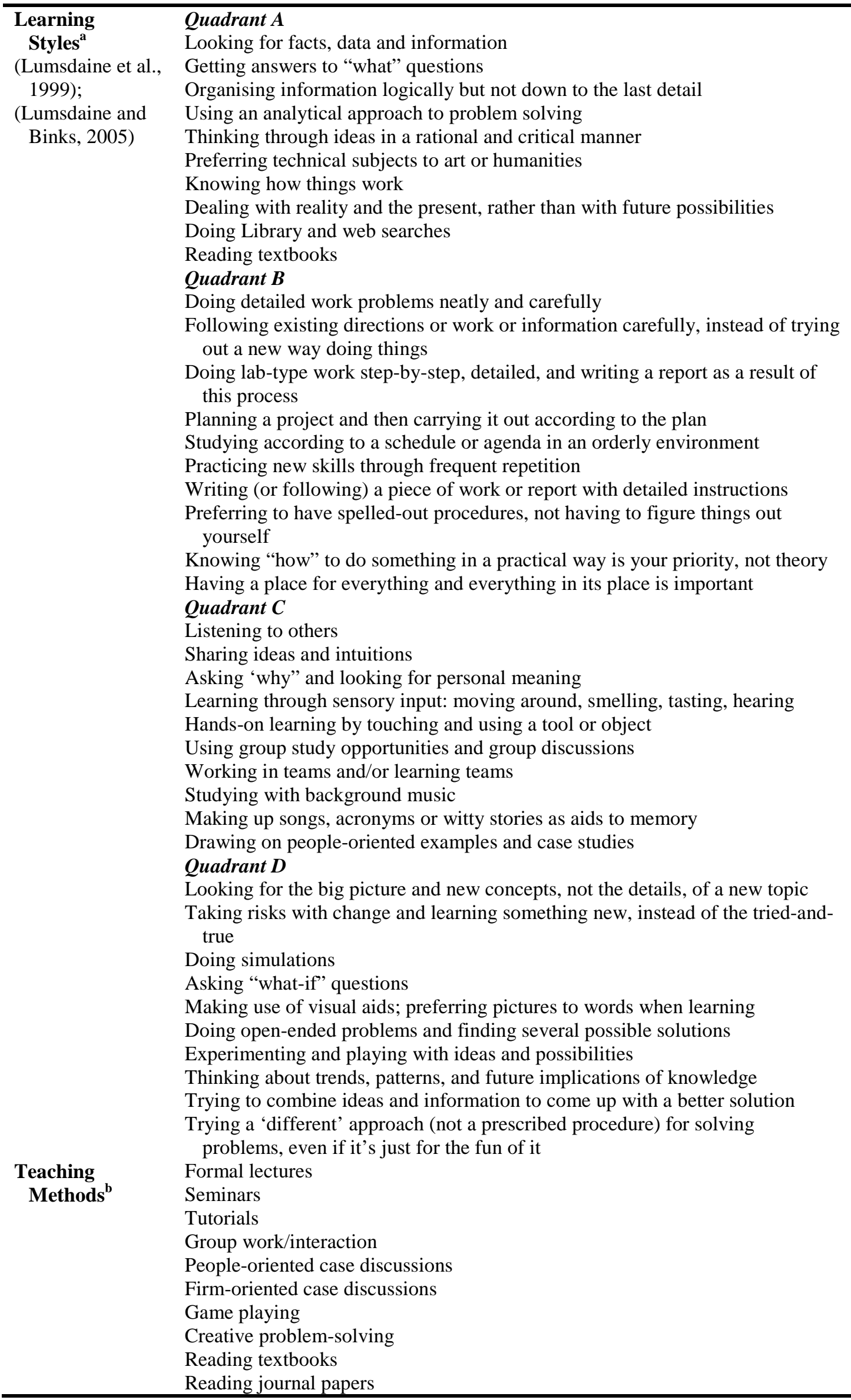




\section{Handouts \\ PowerPoint slides \\ In-class examples \\ Guest speakers}

In-class short exercises

In-class small group exercises

'Homework'

Videos

Role play

Problem-based learning

Self-directed learning

Project-based learning

Class debates

${ }^{\mathrm{a}}$ The following statement anchored the items: Please choose between 12 and 30 of the following types of learning
methods which you think best describes how you approach learning activities and go about your learning...
b The following statement anchored the scale: Please rate the degree to which you like or dislike the following
teaching methods. All items anchored by 7-point agreement scales (1 = "Strongly dislike" to 7 = "Strongly like"). 


\begin{tabular}{|c|c|c|c|c|}
\hline & Mean & $\begin{array}{l}\text { Standard } \\
\text { Deviation }\end{array}$ & Minimum & Maximum \\
\hline \multicolumn{5}{|l|}{ Brain Dominance } \\
\hline A & .496 & .174 & .000 & 1.000 \\
\hline B & .383 & .192 & .000 & 1.000 \\
\hline $\mathrm{C}$ & .413 & .199 & .000 & 1.000 \\
\hline $\mathrm{D}$ & .323 & .204 & .000 & 1.000 \\
\hline E & .439 & .136 & .000 & 1.000 \\
\hline $\mathrm{F}$ & .368 & .163 & .000 & 1.000 \\
\hline G & .410 & .131 & .100 & .850 \\
\hline $\mathrm{H}$ & .398 & .139 & .050 & .950 \\
\hline \multicolumn{5}{|l|}{ Teaching Method } \\
\hline Formal lectures & 4.417 & 1.338 & 1.000 & 7.000 \\
\hline Seminars & 4.716 & 1.207 & 1.000 & 7.000 \\
\hline Tutorials & 5.150 & 1.254 & 1.000 & 7.000 \\
\hline Group work/interaction & 4.613 & 1.566 & 1.000 & 7.000 \\
\hline $\begin{array}{l}\text { People-oriented case } \\
\text { discussions }\end{array}$ & 4.768 & 1.341 & 1.000 & 7.000 \\
\hline $\begin{array}{l}\text { Firm-oriented case } \\
\text { discussions }\end{array}$ & 4.757 & 1.338 & 1.000 & 7.000 \\
\hline Game playing & 4.696 & 1.581 & 1.000 & 7.000 \\
\hline Creative problem-solving & 5.027 & 1.316 & 1.000 & 7.000 \\
\hline Reading textbooks & 3.905 & 1.606 & 1.000 & 7.000 \\
\hline Reading journal papers & 3.676 & 1.548 & 1.000 & 7.000 \\
\hline Handouts & 4.832 & 1.321 & 1.000 & 7.000 \\
\hline PowerPoint slides & 4.905 & 1.405 & 1.000 & 7.000 \\
\hline In-class examples & 5.384 & 1.145 & 1.000 & 7.000 \\
\hline Guest speakers & 4.976 & 1.382 & 1.000 & 7.000 \\
\hline In-class short exercises & 4.611 & 1.393 & 1.000 & 7.000 \\
\hline $\begin{array}{l}\text { In-class small group } \\
\text { exercises }\end{array}$ & 4.363 & 1.542 & 1.000 & 7.000 \\
\hline 'Homework' & 4.147 & 1.541 & 1.000 & 7.000 \\
\hline Videos & 4.968 & 1.422 & 1.000 & 7.000 \\
\hline Role play & 3.978 & 1.670 & 1.000 & 7.000 \\
\hline Problem-based learning & 4.856 & 1.220 & 1.000 & 7.000 \\
\hline Self-directed learning & 4.425 & 1.391 & 1.000 & 7.000 \\
\hline Project-based learning & 4.528 & 1.341 & 1.000 & 7.000 \\
\hline Class debates & 4.606 & 1.533 & 1.000 & 7.000 \\
\hline
\end{tabular}

